\title{
Nomadland y la negación sobre el predicado
}

\author{
Nomadland | Chloé Zhao | 2020 \\ Sergio Zabalza" \\ Universidad Nacional del Chaco Austral, \\ Argentina
}

\begin{abstract}
Resumen
Nomadland es un precioso ejercicio de exploración de aquella zona subjetiva en que la razón, lejos de abandonarse al escepticismo, cede un lugar al horizonte siempre contingente de nuestra existencia. Si el lector encuentra algún símil con la lógica del No Todo que Lacan emplea en sus fórmulas de la sexuación para describir el campo femenino, está en lo cierto. El juicio indefinido, al que Emmanuel Kant apela para resolver las antinomias que las ideas trascendentes imprimen en la razón, brinda sostén a la posición subjetiva de la que Chloé Zhao (directora) y Frances Mc Dormand (actriz y coproductora) hacen gala en este film exquisito, donde un duelo sirve de pretexto para abordar el sentido de la vida; el lugar de los afectos; la finitud; y la relación con los otros, las piedras y la naturaleza.
\end{abstract}

Palabras Clave: No todo | Duelo | Razón

Nomadland and the negation of the predicate

\begin{abstract}
Nomadland is a precious exercise to explore the subjective zone in which reason, far from abandoning itself to skepticism, gives place to the always contingent horizon of our existence. If the reader finds a simile with the logic of not-all that Lacan uses in his formulas of sexuation to describe the feminine field, they are correct. The indefinite trial, to which Emmanuel Kant appeals to resolve the antinomies that transcendent ideas imprint on reason, supports the subjective position that Chloé Zhao (director) and Frances McDormand (actor and co-producer) display in this exquisite film, where a loss serves as a pretext for addressing the meaning of life; the place of feelings; finitude; and the relationship with others, with stones and with nature.
\end{abstract}

Keywords: not all | Duel | Reason

La burbuja financiera que en el año 2008 estalló en Estados Unidos y se diseminó a lo largo y ancho del planeta ha seguido produciendo resonancias. En este caso no nos referimos a consecuencias económicas sino artísticas. En efecto, la película recientemente ganadora de la versión $93^{\circ}$ de los Oscar narra una historia devenida de aquel crack financiero. De hecho, nada menos que Empire es el nombre del pueblo que habitaban Fern (Francis Mc Dormand) y su muy amado marido Bo, cuya muerte coincide con aquel derrumbe económico. Quebrada la empresa en la que trabajaba el hombre, Fern se queda durante algún tiempo para ver cómo el pueblo que albergó años felices se desvanece conforme sus habitantes parten en busca de mejores lugares para sobrevivir.

"Pasé mucho tiempo recordando a Bo" -dice Fern, cuando explica por qué se quedó algunos años en aquel lugar: "si me iba era como si todo aquello no bubiera existido Bo amaba Empire, amaba su trabajo, le encantaba estar allí y todo el mundo lo quería". Lo cierto es que finalmente Fern abandona aquella villa otrora pujante y vital para así formar parte de un fenómeno social que da nombre al film: tierra de nómades. Ese conjunto de personas dedicadas a recorrer las planicies de la pradera norteamericana sin rumbo fijo y tan solo con una casa rodante, furgoneta o vehículo como hogar.

Fern alterna trabajos temporarios con breves estancias en paradores donde conoce personas con quienes compartir la experiencia de sostener la vida, más allá de los habituales menesteres u objetivos a los que la mayoría de los mortales suelen abocarse. Vale mencionar la noche en que los nómades despiden a una amiga mediante el acto de arrojar una piedra al fuego, junto con las palabras que cada uno dejaba partir en esa entrega

* sergiozabalza@hotmail.com 
amorosa y final. Dicho sea de paso, conmovedora instancia que a este escriba le hizo recordar el oportuno comentario vertido por Lacan (1961) durante su seminario dedicado a "La Identificación" cuando - tras homenajear las inscripciones en las cavernas del cazador del desierto-, recomienda a los analistas cuidarse de transformar las palabras en piedras.

En este punto vale destacar el rol que este film le dedica al paisaje, cuya enigmática belleza sirve de marco a ese cuerpo femenino que - conforme transita rutas, kilómetros y encuentros-, adquiere la sensibilidad necesaria para abordar un diálogo entre su propia finitud y la eternidad de esas piedras enclavadas en el desierto. Es aquí donde me gustaría detenerme en un tramo clave de esta historia. Me refiero al diálogo que Fern sostiene con un nómade que había perdido a su hijo, y que sin necesidad de promesas en ningún más allá, le transmite su convicción de que ayudando a los demás lograba honrar la memoria de su ser querido: "yo siempre digo te veré en el camino y es así como ocurre, ya sea un mes, un año o a veces años, los vuelvo a ver puedo estar seguro de que volveré a ver a mi hijo verás a Bo de nuevo y podrán recordar la vida que tuvieron juntos”.

Desde ya, ese "podrás volver a ver Bo y recordar la vida que tuvieron juntos" no consiste en una delirante expectativa de resurrección o efectivo encuentro, en todo caso este interlocutor está diciendo que ella sabrá encontrar a Bo en los ojos, el sentimiento, la piel y el entorno que le devuelvan la sintonía que su marido supo apreciar y compartir. Se trata del límite - en este caso representado por la muerte - al servicio de propiciar algo nuevo, distinto.

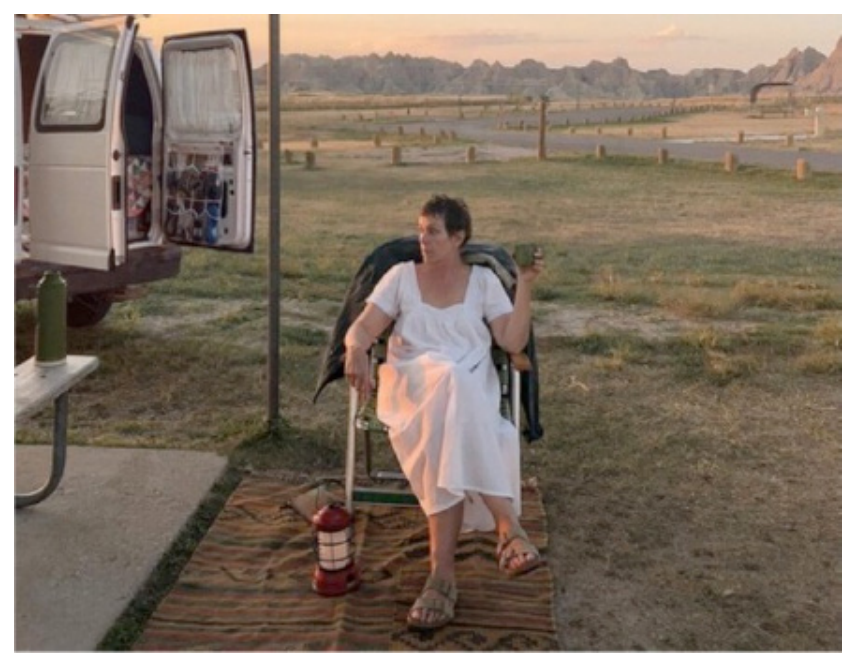

\section{Las antinomias de la razón}

Ahora bien, tal actitud descansa en una apertura cuya naturaleza estriba en una muy especial posición frente las ideas trascendentes que brindan marco a nuestra experiencia vital, algunas de las cuales Kant abordó bajo el sesgo de las antinomias por las cuales la razón "se enreda en tales contradicciones, que se ve obligada a renunciar a su exigencia, en sentido cosmológico" (1781-1787, p. 197).

Al respecto, en su texto "El Sexo y la eutanasia de la razón”, la filósofa norteamericana Joan Copjec (2013) describe el intento de pensar el mundo por el que Kant entiende "el todo matemático de todos los fenómenos y la totalidad de su síntesis” (p. 41). Tal abordaje produce dos proposiciones opuestas respecto de la naturaleza de este todo; una tesis según la cual "El mundo tiene un comienzo en el tiempo y con respecto al espacio está encerrado también en límites" y una antítesis: "El mundo no tiene comienzos ni límites en el espacio, sino que es infinito, tanto en el tiempo como en el espacio" (Kant, 1781-1787, p. 204).

Lo cierto es que para Kant ambas proposiciones son falsas: "El mundus intelligibilis no es nada más que el concepto universal de un mundo en general, en el cual se hace abstracción de todas las condiciones de la intuición del mismo y con respecto al cual, por consiguiente, no es posible ninguna proposición sintética ni afirmativa ni negativa” (p. 207).

Según Copjec (2013), aquí tesis y antítesis en lugar de ser contradictorias, son contrarias. Esto es: la primera (contradicción) es una relación de suma cero donde la negación recae sobre la cópula (el mundo es/no es). En la segunda (contraria) la negación recae sobre el predicado y de esta forma - por no agotar todas las posibilidades -, arroja algo sobre lo cual no se pronuncia. De esta forma; el mundo es No Todo. Lo que en términos kantianos sería un "juicio indefinido" (p. 48).

De hecho, la operatoria analítica que privilegia el efecto de apertura de la interpretación, - es decir: la intervención que conmueve el fantasma de manera que el acto cuente con alguna chance de advenir-, se sirve de una lógica similar: un aspecto no tan conocido de la lógica aristotélica que Lacan, sin embargo, menciona en su seminario “...ou pire”. En el mismo hace referencia a los Analíticos anteriores en los cuales el Filósofo ubica la negación sobre el predicado en lugar de aplicarlo sobre la cópula. Es decir: cita la frase el hombre no es blanco a la que le opone el hombre es no blanco (1971-1972, p.34), 
párrafo que -dice Lacan- de manera sensible deja apreciar otras posibilidades de interpretación.

\section{A modo de breve conclusión}

Desde esta perspectiva entiendo que Nomadland es un precioso ejercicio de exploración de aquella zona subjetiva en que la razón, lejos de abandonarse al escepticismo, cede un lugar al horizonte siempre contingente de nuestra existencia. Si el lector encuentra algún símil con la lógica que Lacan emplea en sus fórmulas de la sexuación para describir el campo femenino, está en lo cierto. No por nada, Chloé Zhao (directora) y Frances Mc Dormand (actriz y coproductora) hacen gala de tal condición a lo largo y ancho de este film exquisito, donde un duelo sirve de pretexto para abordar el sentido de la vida; el lugar de los afectos; la finitud; y la relación con los otros, las piedras y la naturaleza.

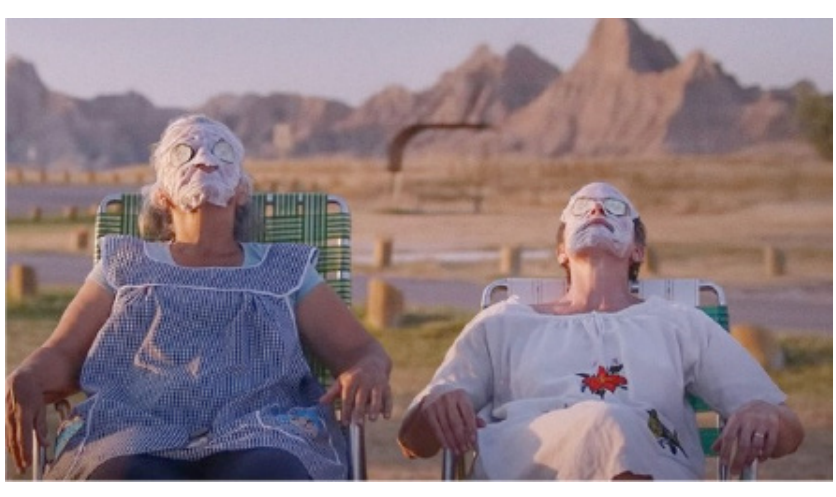

Para terminar, se hace notable observar que las reglas del actual orden financiero mundial -las mismas que en el año 2008 provocaron el más arriba mentado derrumbe social y económico- pretenden enmascarar con un falso orden racional -un Todo- lo que en definitiva no es más que un disparatado y mortífero sistema enemigo de lo humano.

\section{Referencias}

Copjec, J. (2013). El sexo y la eutanasia de la razón. Paidós.

Kant, M. (1781-1787). Crítica de la Razón Pura. México Porrúa.

Lacan, J. (1961). Clase del 13 de diciembre de 1961. En El Seminario: Libro 9, La identificación. Inédito.

Lacan, J. (1971-1972). El Seminario: Libro 19, “...ou pire”. Paidós.

Zhao, C. (directora). Nomadland [película]. Searchlight Pictures, Walt Disney Pictures 